\title{
Utilidad de la radiografía panorámica dental digital en la estimación de la edad en adultos.
}

\author{
Usefulness of dental digital panoramic radiography in the \\ estimation of age in adults.
}

\section{Landaํ, PM. Garamendi², MC. Botella³ e I. Alemán ${ }^{3}$}

\begin{abstract}
RESUMEN
La estimación de la edad constituye un campo de creciente interés dentro de la Medicina Forense. La cuantificación de la reducción de las dimensiones de la cavidad pulpar como consecuencia del proceso de depósito de la dentina secundaria a lo largo de la vida podría servir como un posible indicador de edad. Este fenómeno además de mediante técnicas morfológicas, puede ser analizado mediante la utilización de diferentes técnicas radiográficas. El objetivo principal de este estudio consistió en evaluar la reproducibilidad del método original de cálculo de edad dental desarrollado por Kvaal et al. sobre radiografías panorámicas digitales dentales así como analizar la aplicación de las fórmulas de estimación de edad dental propuestas. Fueron seleccionadas al azar 100 ortopantomografías digitales obtenidas de pacientes de una clínica de Bilbao de edades comprendidas entre 14 y 60 años. En cada ortopantomografía fueron estudiados tres dientes mandibulares siguiendo la metodología ya descrita. Los resultados obtenidos no confirmaron la reproducibilidad del método desarrollado por Kvaal et al. sobre radiografía digital directa. Los valores tan extremos obtenidos en la estimación de la edad mediante la aplicación de las fórmulas de regresión analizadas sobre las radiografías digitales de esta serie de estudio desaconsejan su aplicación en poblaciones similares a la serie analizada.
\end{abstract}

Palabras clave: dentina secundaria, estimación de edad, ortopantomografía dental, radiología digital.

Cuad Med Forense 2008; 14(52):127-135

Artículo traducido al castellano del original aceptado para publicación en Int $\mathrm{J}$ Legal Med (DOI 10.1007/s00414-008-0268-9; http://dx.doi.org/10.1007/s00414-008-0268-9)

Reproducido con autorización de Springer, Heidelberg, Alemania.

Fecha de recepción: 09.JUL.08

Fecha de aceptación: 29.SEP.08

Correspondencia: Dra. Maㅡ Irene Landa. Servicio Clínica Médico Forense. Subdirección de Vizcaya. Instituto Vasco de Medicina Legal. C/ Buenos Aires, 6. 48001 Bilbao. E-mail: landairen@gmail.com

1 Médico Forense. Instituto Vasco de Medicina Legal, Subdirección de Vizcaya.

2 Médico Forense. Instituto de Medicina Legal de Huelva.

3 Antropólogo Forense. Laboratorio de Antropología Física, Facultad de Medicina, Universidad de Granada. 